\title{
Technologies for the bachelors-designers' artistic abilities development
}

\author{
Irina Protopopova ${ }^{1, *}$, Olga Kartavtseva $^{2}$ \\ ${ }^{1}$ FS EI Don State Technical University, 1, Gagarin sq., 344000, Rostov-on-Don, Russia \\ ${ }^{2}$ FSAEI Southern Federal University, 105, B. Sadovaya str., 344000, Rostov-on-Don, Russia
}

\begin{abstract}
The artistic abilities' development is considered as the spiritual and creative development of an individual. The structure of the artistic abilities and the psychological and pedagogical conditions of their development are analyzed. The structure and content of the technology for the abilities, principles, methods and conditions development for its implementation are considered. The innovative technology content for the development of the bachelors' artistic abilities is described, where the abilities turn into strengths and abilities of an individual.
\end{abstract}

\section{Introduction}

The development of the students' artistic abilities is directly related to the spiritual revival of a society in which, on the one hand, innovative processes are present, and on the other, there is a global crisis in all human activity areas. The spiritual content in a person is the spirit or his original creative force, which should be manifested in the creative activity acts. This was written by N.A. Berdyaev, I.A. Ilyin, V.S. Soloviev, N.O. Lossky, B.P. Vysheslavtsev, S.L. Frank K.G. Jung, E. Fromm. Research and other discoveries in the field of spiritual development of a personality. The works of A.A. Ukhtomsky, M.M. Bakhtin, M.K. Mamardashvili, L.N. Gumilev, V.I. Vernadsky, A. Maslow, V.A. Petrovsky, V. Frankl, Jung and others are particularly relevant today, they describe the spiritual processes' foundations in creativity. N. A. Berdyaev explained the purpose a human by the fact that he is burnt to show his deep creative power in creativity acts. [3]. Traditionally, the spiritual development of a person by means of art occurs by means of the human's creative artistic abilities development; without this stage it is impossible to develop the strength-abilities.

Various theories of creativity deal with many aspects of personal development. Creativity is considered by E. Fromm and G. Allport as a way of a person's life in which a person is the creator of his destiny. E. Fromm at the same time calls the man-creator an integral person who has a constant connection with the source of his creative powers. [14]. In humanistic psychology A. Adler, A. Maslow, C. Rogers also believed that initially a person has creative power and that his creative "Me" influences every facet of the human experience [10]. K.G. Jung, while studying the processes of creativity, noted that if creative power does not manifest itself in the creativity of an individual, then it becomes destructive and uncontrollable from creative [15]. V.A. Petrovsky noted that among other well-known

\footnotetext{
* Corresponding author: conkurschudo@gmail.com
} 
abilities, a personality developed an ability that he called the "creative aspiration", which indicates that the personality acts under the influence of internal strength and its internal motivation prevails over the external motivation [12]. Modern educators pay great attention to the development of various abilities of the bachelors-designers, bachelors-architects, including their creative thinking. [5]. We believe that the current stage of higher education can be considered as a stage in the development of a person's strengths [7], allowing him to be successful, competitive. Initially, the creative development of the personality of the students studying design as a stage in the development of his artistic abilities begins in the pre-university period, in a higher educational institution they continue to develop and pass into their strength-abilities. The problem of the artistic abilities' development was considered by L. S. Vygotsky, S. L. Rubinstein, A.N. Leontiev, A.V. Petrovsky, B.M. Teplov, E.I. Ignatiev, N.N. Volkov, V.I. Kireenko, V.S. Kuzin et al.

Kuzin V.S. defines the creative abilities as an emotional attitude, especially developed aesthetic feelings for the perceived and depicted phenomenon. [9]. It is known that abilities are the mental functions of a personality, aimed at the activity's specifics. Abilities develop only in activities. Creative abilities are those that make it possible to create new abilities that he has never possessed before, and design is an innovative activity and is carried out due to these abilities. The first thing a teacher deals with, realizing the technology for developing abilities, is attention and perception of students, they are a single process, they have the same characteristics: depth, concentration, volume. Visual perception has its specific characteristics: meaningfulness, integrity, selectivity, apperception, constancy. The features of visual perception, its types and characteristics are presented in the works of N.N. Volkov, V.I. Kireenko, E.I. Ignatiev, V.S. Kuzin and others.

There is a certain hierarchy of abilities and a sequence in their development. There are the basic fundamental abilities, there are the abilities of a complex form, there are higher abilities. Higher abilities are the abilities - the forces of personality. The rule in the development of abilities is that artistic abilities develop immediately, but at different speeds, affect each other's development, and in the end, they can form the integral complex formations in the synthesis. So creative imagination is a synthesis of many abilities: visual perception, visual memory, visual figurative representations, creative thinking, compositional representations, sense of form, sense of construction, space sense and others. The technological approach is the most effective in the development of the bachelordesigners' artistic abilities. The issues of content and implementation of various technologies were considered in the research of V.M. Monakhov, B.T. Likhachev, V.P. Bespalko, G.K.Selevko, M.V. Clarin, I.P. Volkov, V.M. Shepel and other scientists. In our study, pedagogical technology is developing as a model of joint activity of students and a teacher to achieve the goal: the development of artistic abilities, abilities - the forces of bachelorsdesigners in the most comfortable conditions.

\section{The structure of artistic ability}

Artistic abilities for the design activities can be divided into three areas of personality: intellectual, emotional-sensual and physical. So, in the intellectual sphere of the personality include: all types of thinking: analytical thinking, which makes it possible to analyze the objects, form, thought processes of synthesis, abstract thinking, which allows to highlight the abstract phenomena such as proportions in the object, associative thinking, creative thinking, adaptive, spatial thinking, project thinking, and in general - professional design thinking. The abilities associated with visual perception: visual perception of nature, form, space, visual perception of a planar image, visual and figurative representations are particularly distinguished. All other artistic abilities depend on visual perception; therefore, all types of visual perception are the basic fundamental abilities. 
The emotional and sensual sphere of personality includes the following abilities: a sense of color, a sense of form, a sense of design, a sense of line, a sense of plane, a sense of space, a sense of tone, a sense of proportion, a sense of mass, a sense of color, a sense of rhythm, a sense of contrast, a sense of texture, etc. The physical sphere of the personality includes the abilities associated with the actions of the hands in a specific design activity, they are called the action "in form", motor actions, visual actions or graphic movements. These abilities are associated with the technical execution of the design project in the material, and being developed, make it possible to make a project with high functional and aesthetic qualities, where the form is "lively" and expressive, the space is movable, etc., where all the artistic means of expression are presented in synthesis and stylistic integrity. Ultimately, the abilities of all spheres of personality merge into a single psycho-physiological process, called the system of visual-verbal-motor associations.

There are various artistic abilities associated with visual perception: visual perception of the form, visual perception of the image, observation, silhouette vision, holistic vision, tonal vision, pictorial vision, constructive vision, volumetric vision, acute visual sensitivity, visual memory, visual perception of volume and visual perception of a planar image described by N.N. Volkov as two different abilities [4]. Visual perception has a special place in the hierarchy of abilities - it is a basic fundamental ability. The first is the visual perception of the form, and this is natural, later the perception of the image. Visual perception has the following characteristics: concentration, speed, volume, these characteristics in the process of creative development of a person change qualitatively. Ultimately, the basic abilities are combined into integral structures in which the intellectual, emotional, sensual and physical spheres of the personality participate, they are coordinated, act as a whole, and then it is possible to talk about a certain level of a person's artistic development. These integral structures are the complex-shaped abilities and represent the integral formations that arose on the basis and synthesis of the basic abilities: artistic-figurative representations, artisticfigurative thinking, compositional-spatial representations, figurative representations, figurative vision, compositional-figurative representations, figurative spatial representations, etc.

The features of the adaptive process of bachelors-designers of junior courses are connected with the complexity of the transition from the basic abilities to the complex-form abilities, and this should be taken into account by a teacher who implements a developing technology. What is the difference between the basic abilities and the abilities of complex shape, characteristic of the designer? Basic abilities are the consciousness reaction to the outside world. The complex shaped abilities are the result of the "internal work" of a personality with the material of "reactions" or visual reflections, and here the personality is closer to the creative power source, in the process of creativity this connection is strengthened, the creative power of the personality grows. The integrity of complex-shaped abilities, as well as the highest artistic abilities, make it possible to call them the abilitiesforces, since they manifest a more holistic creative power of a person than in the basic abilities. Many abilities in design activity turn into the abilities-forces, among them: the holistic perception, holistic representations, holistic thinking, intuition. So, having a holistic perception, a person is able to see the new and create it, which in turn is the ability to innovate, so in demand in the modern society. Higher abilities include: creative imagination, artistic worldview, the need for creative activity, as the highest aesthetic need, aesthetic and artistic taste, creative aspiration. They are also the abilities - forces of a creative person, they were possessed by all the creators whose works entered the history of art, the history of design and architecture, therefore art is a spiritual value. 


\section{The content of the technology for the bachelors-designers artistic abilities' development and the conditions for its implementation}

Pedagogical technology is a system category, the structural components of which are: learning objectives, learning content, means of pedagogical interaction, organization of the educational process, student, teacher, activity result [11]. The purpose of a developing technology is to develop the bachelors' artistic abilities and strength-abilities for the design activities. In order for the developing technology's implementation to be successful, the teacher should know the artistic abilities' structure, psychological and pedagogical features and the conditions for their development, to have the developed abilities and abilities, strengths himself.

The objectives of the developing technology are: creating optimal conditions for the successful development of the bachelors' abilities, using the effective approaches and tools in the technology implementation. The tasks also include the abilities development principles' implementation and the application of methods that intensify the process of developing the artistic abilities for the bachelors-designers. The structural element of the technology "student-teacher" is an integrating element, since all the abilities of students can be developed under the influence of awakened and active abilities, the forces of the teacher. Therefore, the developing technology is integrated, where all its other elements are integrated around the main element of the "student-teacher" technology: conditions, means, principles, methods, approaches.

The content of the technology is characterized by a connection between developing tasks and educational tasks, since artistic abilities develop mainly in the educational process. These abilities of the bachelor-designers are developed in the process of mastering various disciplines. For example, the educators-designers write that painting classes well developed among the students the basics of conditional decorative vision of form and color, help to identify the personal qualities, manner and style, understanding the "movement" of a plane or objects in space, to understand the visual interaction of form and space, to transfer the displacement skills of the composition center or the creation of a composition with an inclination, the ability to schematically convey the form, the tendency to artistic synthesis [1].

The technology also provides for the presence of specially organized classes in elective courses, where the development of certain artistic abilities takes place especially intensively. The following approaches are used in the implementation of the technology: empirical, existential, personality-oriented, individual, human-personal. Empirical provides the student with full development through a conscious personal experience of creativity. The existential approach is realized in that the student is open to new experience, due to which the development of his artistic abilities takes place. Personal orientation involves the teacher taking into account all the personal needs of the developing personality of the bachelor and providing him with this opportunity, including pedagogical support. An individual approach to the student's development is important in the case of certain "falling" abilities of a student and in many cases when the student's personality causes the teacher to use the new techniques, methods, and means of influence. The human-personal approach means that in the technology implementation not only the intellectual state of all participants in the process is taken into account, but also their feelings. Therefore, it is important to implement the principle of mutual trust in technology, since only in a state of trust the students' perception remains "open", in this case the development is intensive and with psychological comfort.

Among the principles for the developing technology implementation, the main one is the visibility principle. Its implementation activates the development of all artistic abilities. The principle of managing sensory experience is no less important in developing technology, 
when, through visualization, the teacher can transfer his experience of the sense of color, sense of form, sense of space, to the students, he can also control any of his sensory experience from the field of design activity. The teacher's method of observing the abilities development is used in the implementation of all approaches and principles in our technology. It also means that the teacher, in addition to the developed artistic abilities, forces, has developed reflection and empathy.

The principle of "staying here and now" is universal in modern education, its implementation in developing technology ensures maximum student attention to activities, full concentration on it and this makes possible to show the creative power in the activities without loss. The methods for the technology implementation for the development of the bachelors' abilities are pedagogical drawing, pedagogical support. Their forms can be different: common for all students to ensure the collective cognitive activity and individual in working with one student, the visual activity types of a teacher can also be different, from fragmentary pedagogical drawing to a long master class.

The principle of intensive development of abilities is implemented in the process of training intensification, where fast visual, design activities are needed. It is intense activity that accelerates the abilities' development, contributes to their synthesis and the creation of new holistic formations, called the abilities - forces.

Design teachers write that the initial hand-made sketch of a project, in its incomplete drawing, conciseness and generalization, stimulate further creative activity and the best expression of the purpose it can be a quick sketch, made with colored pencils, watercolors, or a long sketch with the drawing of details [2].

Among the methods intensifying the bachelors' abilities developing process, an important place is occupied by the method of pedagogical drawing, when the "live" activity of a teacher, graphic or design, is an example of intense and at the same time light, spontaneous activity. The principle of "expanding and deepening the perception" by students is implemented everywhere by the teacher in technology, since it is through perception, through the "main door" that everything enters the student, that is connected with the development of abilities, visual information, sensual artistic experiences, and here the teacher uses all forms of transmission sensory abilities, holistic states of personality and practical skills.

The principle of the holistic perception development is one of the important principles in the technology implementation for the bachelor-designers abilities' development. It is implemented in the process of accumulating experience in creative activities in the field of design and experience in completing tasks in order to create a holistic image. The culmination in the development of abilities is the period when abilities go into the stage of integrity, when the bachelors have a holistic perception, holistic figurative representations, they are visible when a student creates an integral design product.

The students' perceptions and attention change qualitatively, they become concentrated, their volume increases, and activity becomes spontaneous and intense. These are the signs that abilities turn into abilities-forces, and their signs appear: joy, markedly increased performance, there is a special psychologically comfortable state called creative satisfaction. The principle of the internal motivation priority over external in students arises as an evidence of the abilities' transition into abilities-forces, since they no longer act under the influence of external motivation, but are motivated by the movement of internal creative power, hence the spontaneity of creative activity. It can be clarified that pedagogical support corresponds to the methods of nature-like development of a personality, when the development process is coordinated with the mental abilities and needs of the student, it is carried out without stress and emotions, which are the obstacles in the abilities' development. 


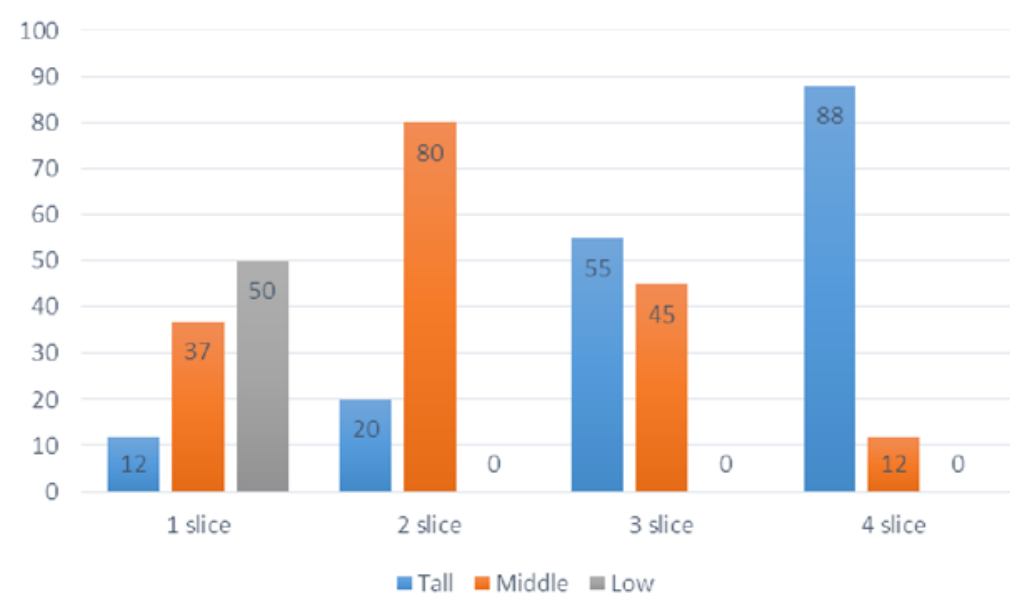

Fig. 1. Dynamics of the growth of artistic abilities in the control group.

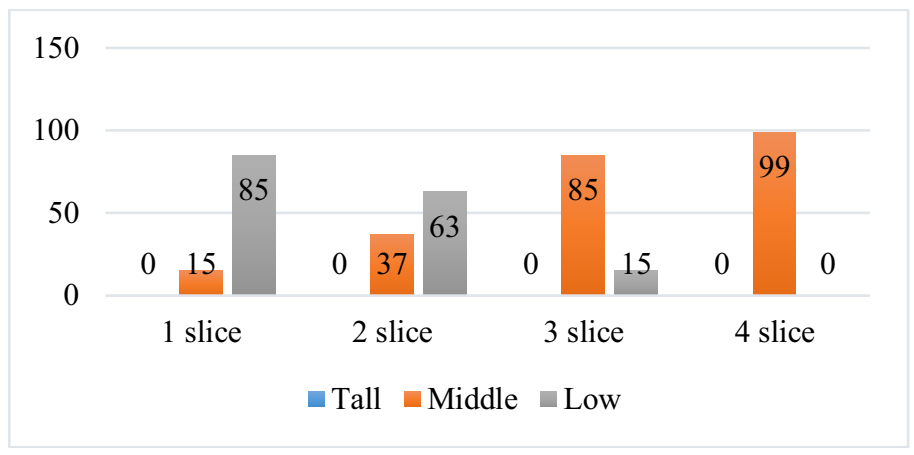

Fig. 2. Dynamics of growth of artistic abilities in the experimental group.

The conditions for the bachelor-designers' abilities development also include the organization and conduct of the socially active nature motivating events: the participation of students in Olympiads, exhibitions, competitions of various levels, including international events.

\section{Summary}

1. In our opinion, during the period of university education, bachelors-designers develop not only artistic abilities, but also abilities-forces characteristic of a competitive and successful person.

2. The signs of strength-abilities in a personality are the complex-shaped abilities, characterized as integral psychological formations: holistic perception, holistic imaginative vision, holistic understanding, holistic representations, intuition. A person who has strengthabilities is defined as a holistic personality, a creator-personality. An integral personality is characterized by a high concentration of attention and perception, their large volume, and their creative activity is spontaneous and intense.

3. The process of developing the artistic abilities of bachelors-designers and their abilitiesforces is effective if in the technology implementation:

- traditional and innovative approaches are used: empirical, existential, personality-oriented, individual, humane-personal;

- The applied methods: observation method, method of pedagogical drawing, pedagogical support. The technology uses nature-friendly (non-violent) development methods: attention 
to each student, empathic identification with the student, his inspiration, support of his strength, respect for the student;

- the following principles are implemented: the principle of visualization, the principle of managing sensory experience, the principle of "expanding and deepening perception", the principle of open perception, the principle of "staying here and now", the principle of mutual trust, the principle of the intensive abilities' development, the principle of developing holistic perception, the principle of priority of internal motivation over external;

- the following conditions are met - the educational environment is saturated with modern didactic tools, innovative teaching technologies, the bachelors' development takes place in traditional classes and in the system of special courses by choice, electives, the teacher has developed the artistic abilities, strengths, pedagogical reflection and empathy, if the motivating events of a socially active nature are organized and conducted: the students' participation in Olympiads, exhibitions, competitions of various levels, including international events.

4. Modern education can be considered as a stage in the development of the students' powerabilities, the development of a holistic personality capable of innovation.

\section{References}

1. V.S. Akopyan, M.B. Pokhlebaeva, Design education: problems and prospects: scientific works collection (Krasnodar, Kuban state university, 2016)

2. L.V. Baeva, L.M. Boldyreva, Design education: problems and prospects: Sat. scientific $\operatorname{tr}$ (Krasnodar, Kuban state University, 2016)

3. N.A. Berdyaev, The meaning of creativity. Russian Philosophy, Names. Teachings (Moscow, 2001)

4. N.N. Volkov, The perception of the subject and the picture (Moscow, Publishing House of the Academy of Pedagogical Sciences of the RSFSR, 1950)

5. N.Y. Zakharova, I.V. Protopopova, V.A. Shepilova, Yu.G. Likhovid, IOP Conference Series: Materials Science and Engineering 698(3) 2019 https://doi.org/10.1088/1757899X/698/3/033018

6. O.D. Kartavtseva, The spiritual development of personality on the basis of self-realization of the essential forces in creativity (Mn. Rostov-n/D, IPO PI SFU, 2009)

7. O.D. Kartavtseva, The scientific foundations of existential pedagogy (Rostov on Don Ministry, SFU, 2011)

8. I.A. Ilyin, The path of spiritual renewal (Moscow, 1993)

9. V.S. Kuzin, Psychology (Moscow, Agar, 1999)

10. A. Maslow, Motivation and personality (Peter, 2007)

11. V.S. Cuckoo, Pedagogical technology (Rostov n / D, Phoenix, 2010)

12. V.A. Petrovsky, Personality in psychology: the paradigm of subjectivity (Rostov-onDon, 1996)

13. N.A. Sablina, Design education: problems and prospects: Sat. scientific tr (Krasnodar, Kuban state. University, 2016)

14. E. Fromm, Escape from freedom (Minsk, Man for himself, 2000)

15. K. Jung, On the energetics of the soul (Moscow, 2008)

16. N.Yu. Zakharova, I.M. Vlasova, I.V. Protopopova, R.L. Lukyanov, IOP Conference Series: Materials Science and Engineering 698(3) (2019) https://doi.org/10.1088/1757899X/698/3/033013 